\title{
VESSEL MIXERS WITH VIBRATION ACTIVATOR IN CONSTRUCTION ENGINEERING
}

\author{
Victor Kuzmichev" ${ }^{1}$, Vladimir Verstov ${ }^{2}$ \\ ${ }^{1}$ Peter the Great Saint Petersburg Polytechnic University, \\ Polytechnicheskaya st. 29, St. Petersburg, Russia \\ ${ }^{2}$ Saint Petersburg State University of Architecture and Civil Engineering \\ Vtoraja Krasnoarmejskaja ul. 4, St. Petersburg, Russia \\ ${ }^{1}$ kuzmichev_va@mail.ru, 2 5750195@mail.ru
}

\begin{abstract}
Construction mixes are classified as polydisperse heterogeneous systems, where surface phenomena occurring at the phase interface, exert a great influence on formation of such systems. As for mixing processes, adsorption and diffusion are the most important ones. Their speed depends on mobility of mineral constituents' particles, size of the active interfacial area, binder dispersion, technological peculiarities of the process and other factors. It is known that the vibration is one of the ways to increase mixing intensity. The article presents original designs of vessel mixers of forced action with vibration activators placed inside the mixing chamber. A vibration activator is installed in "dead" zones located along the geometrical axis of the mixing chamber where intensity of convective mixing is low.

Methods of design of balanced eccentric vibration activators of precessing and plane-parallel type are considered. Results of production tests with regard to industrial designs of vibration mixers are presented. Considerable attention is paid to measurement of the vibration level reflecting the quality of dynamic balancing of the vibration activator. Vibrational impact on the environment and maintenance personnel amounts to $\approx 5 \mathrm{~m} / \mathrm{s}^{2}$, corresponding to standard values for processing equipment as per GOST 22061-76.
\end{abstract}

\begin{abstract}
Keywords
Vessel mixer, vibration activator, design methods, dynamic balancing.
\end{abstract}

\section{Introduction}

Manufacturing of various building products (concrete slabs, blocks, bricks, paving slabs, etc.) is inseparably associated with preparation of mixes from which they are formed. The mix quality characterized by the degree of its approximation to the material with a certain ideal order of distribution of separate components and uniformity of physical and chemical properties is mainly defined by efficiency and intensity of mixing. The latter is derived from design features of mixing equipment.

Mixing of materials is a mechanical process resulting in uniform distribution of mineral constituents' particles and a binder in a mixed volume, which, in their turn, form a uniform mix (Bosch et al., 2016; Zhang et al., 2016).

Based on the developed ideas, the following types of mixing are distinguished:

1) convective mixing, i.e. moving of particle groups from one position to another by transfer, introduction, sliding of layers, layer portion deformation or attrition as a result of mechanical movement of operating elements of mixers;
2) diffusive mixing, i.e. gradual redistribution of particles of various constituents through the phase interface.

Convective mixing is classified as a macromixing process while diffusive mixing is classified as a micromixing process. Along with mixing, separation takes place in a mixer (separation of constituents' particles and their concentration in certain areas of the mixer body under the action of gravitational, centrifugal and inertial forces).

Actual mix formation usually represents superposition of mixing and separation.

Upon mixing in mixers of various types, the mix structure changes continuously and, therefore, its structural and rheological properties change. Control over structural and rheological properties is the main direction of intensification of the diffusion component with regard to mixing processes. At the present time, the following methods are used: pseudo-liquefaction, use of surface active agents (SAA) ensuring mix viscosity reduction; supply of binder feeding by means of nozzles, etc.

Vibration is one of the widely applied types of mechanical impact on environments in the field of construction and production of construction materials, considerably affecting changes in rheological properties of mixes 
(Bauman, Bykhovsky, 1977; Blekhman, 1994; Verstov et al., 2013; Chelomey, 1981; Efremov, Lobanov, 2008; Efremov, Lobanov, 2009; Kuzmichev, 2013; Kuzmichev, 2014).

\section{Design description}

Designs of vessel (rotary) mixers (hereinafter - vibration mixers) with vibration activators placed inside the mixing chamber are presented below. It is expedient to install a vibration activator in "dead" zones located along the geometrical axis of the mixing chamber where intensity of convective mixing is low.

A mixing chamber, mixing mechanism, vibration activator, drives of the mixing mechanism and vibration activator are the main structural components of mixers. It is expedient to make a discharge opening at the mixing chamber bottom along the vertical axis of symmetry, ensuring efficient vibration treatment of the entire mix volume during discharge.

Mixing in similar mixers is carried out by means of combination of mixing mechanism rotation and mix exposure to vibration of the vibration activator ensuring intensification of thixotropic transformations.

Industrial designs of vibration mixers operating for years have been designed (Figure 1 and 2).

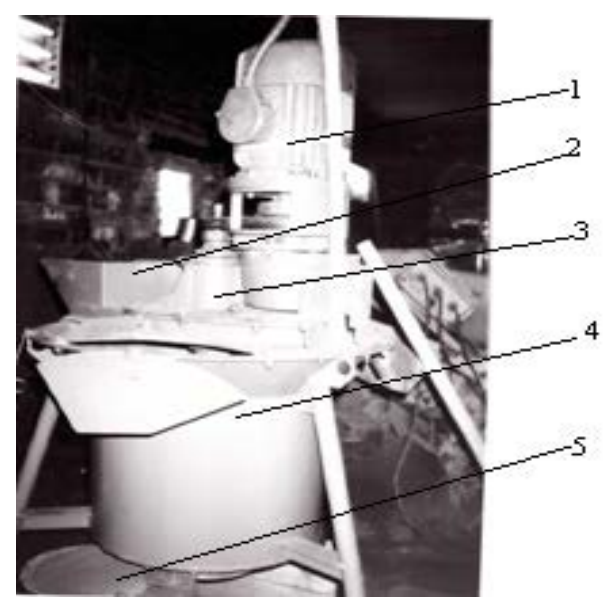

Figure 1. Vibration mixer of cyclic action:

1. drive; 2. charge opening; 3 . vibration activator of precessing type; 4. mixing chamber; 5 . discharge opening. Author's certificate 2033324 Class B 01F 11/00
Table 1. Technical characteristics of vibration mixers of batch action

\begin{tabular}{|c|c|c|}
\hline Type & $A$ & $B$ \\
\hline $\begin{array}{l}\text { Prepared batch } \\
\text { volume, } \mathrm{m}^{3}\end{array}$ & 0.08 & 0.1 \\
\hline $\begin{array}{c}\text { Vibration } \\
\text { parameters of a } \\
\text { vibration exciter: } \\
\text { - maximum } \\
\text { oscillation } \\
\text { amplitude, mm } \\
\text { - oscillation } \\
\text { frequency, rad/s } \\
\text { - maximum } \\
\text { acceleration of } \\
\text { oscillations, m/s }{ }^{2} \\
\text { - type of } \\
\text { oscillations }\end{array}$ & $\begin{array}{r}3.5 \\
230 \\
185 \\
\text { precessing }\end{array}$ & $\begin{array}{c}2.0 \\
260 \\
135 \\
\text { plane-parallel }\end{array}$ \\
\hline $\begin{array}{c}\text { Rotation } \\
\text { frequency: } \\
\text { - of spiral blades, } \\
\mathrm{rad} / \mathrm{s} \\
\text { - of a truncated } \\
\text { cone, } \mathrm{rad} / \mathrm{s}\end{array}$ & 1.5 & 15 \\
\hline $\begin{array}{c}\text { Geometrical } \\
\text { parameters: } \\
\text { of a vibration } \\
\text { exciter: } \\
\text { - diameter, mm } \\
\text { - length, mm } \\
\text { of a mixing } \\
\text { chamber } \\
\text { of a mixing } \\
\text { chamber: } \\
\text { - diameter, mm } \\
\text { - height, mm } \\
\text { - Installed power } \\
\text { of electric motor, } \\
\text { kW }\end{array}$ & $\begin{array}{l}130 \\
500 \\
\\
\\
\\
600 \\
570 \\
5.5\end{array}$ & $\begin{array}{c}730 \\
700 \\
3.0\end{array}$ \\
\hline $\begin{array}{l}\text { Dimensions: } \\
\text { - width, m } \\
\text { - height, m } \\
\text { - length, m } \\
\text { - Mass, kg }\end{array}$ & $\begin{array}{l}1.5 \\
1.9 \\
1.5 \\
650\end{array}$ & $\begin{array}{c}1.0 \\
2.3 \\
1.0 \\
730\end{array}$ \\
\hline
\end{tabular}



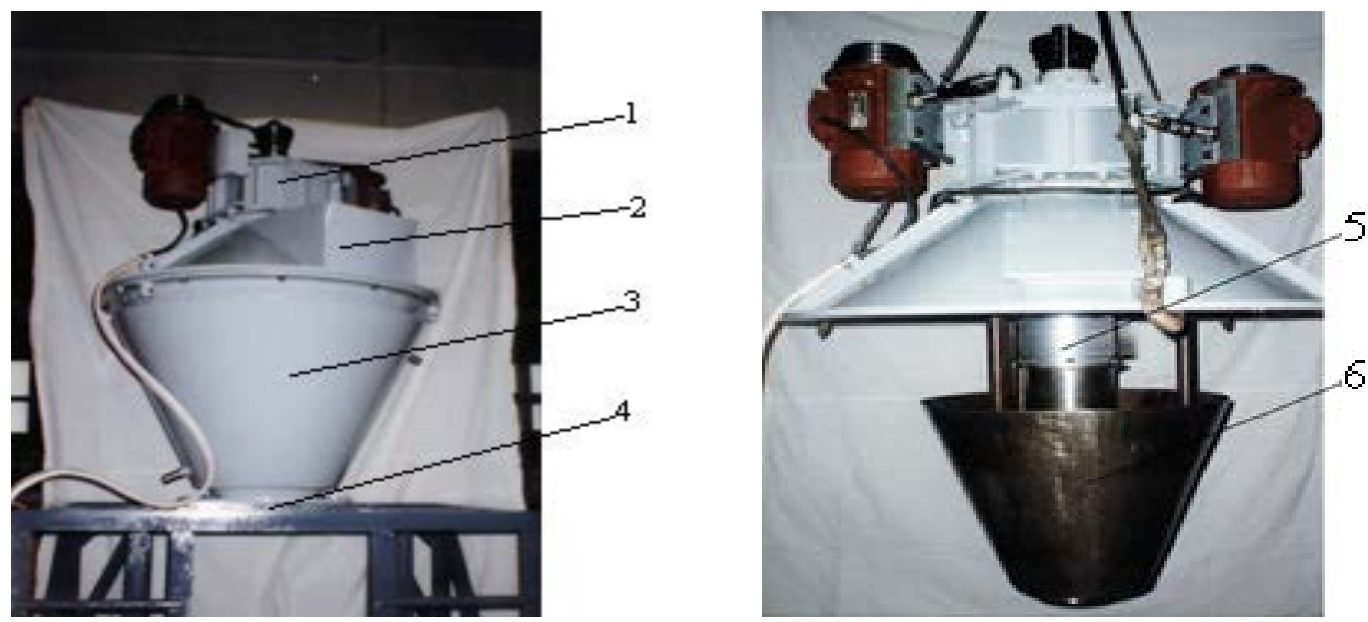

Figure 2. Vibration mixer of cyclic action:

1. drive; 2 . charge opening; 3 . mixing chamber; 4 . discharge opening;

5. vibration activator of plane-parallel type; 6 . mixing mechanism

Patent for invention No. 2510873 Class B 01F 11/00

Figure $3 b$ shows processing equipment for production of stones of soil-concrete mixes (unburned brick) with a capacity of 40 pieces per hour. The vibration mixer presented in Figure 1 was used as mixing equipment.

Investigation results with regard to mixing in a vibration mixer ( $B$ type) intended for mixing of highly-concentrated fine-dispersed mixes are presented below. A plane-parallel vibration activator and mixing mechanism in a form of a truncated cone, combination of which ensures increased intensity of mixing, are placed in the mixing chamber. Mixes consisting of clay and water with a viscosity of 150 $\mathrm{Pa} \cdot \mathrm{s}$, chalk and water with a viscosity of $90 \mathrm{~Pa} \cdot \mathrm{s}$ as well as food compositions made of flour, cocoa powder and water with a viscosity of $270 \mathrm{~Pa} \cdot s$ were used as models.

The profound study of mixing at the microlevel was performed with use of the mix consisting of chalk and water, to which insoluble black powder was added as a tracer agent (indicator). Results of the microscopic analysis of comparison of mixing quality with and without vibration are presented in Figure 4.

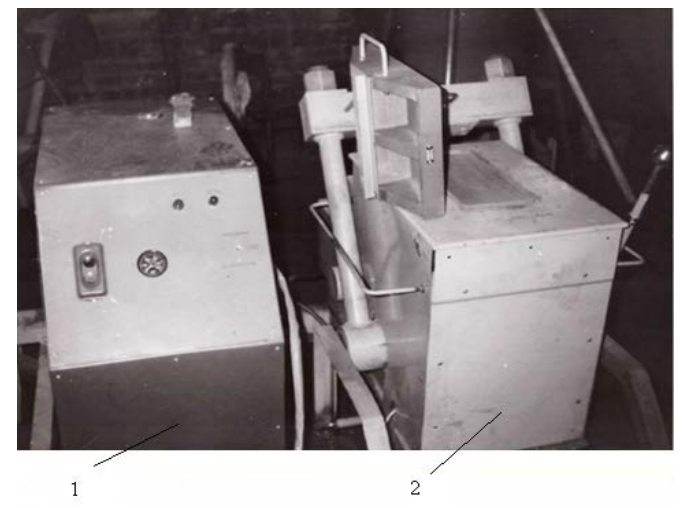

Figure 3. Processing equipment: 1. control board; 2. UPG-120 press
It is obvious that vibration mixing ensures a more uniform mix characterized by uniform distribution of black powder grains in the sample.

\section{Technique of balancing of vibration activators}

Let us consider calculation of a console precessing three-point vibration activator presented in Figure 5 and installed in a vibration mixer (A type). The vibration activator consists of carrying drive shaft 1 , main bearings 2 , body 3 , rod bearing 4 installed on the eccentric bushing with mechanically set eccentricity $e$, counterbalances 5, coupling 6 located concentrically in relation to the carrying drive shaft.

Upon rotation of the carrying drive shaft, the vibration activator body executes a precessing motion with the shaft rotation frequency and nutation angle:

$$
\beta=\operatorname{arctg} e / L
$$
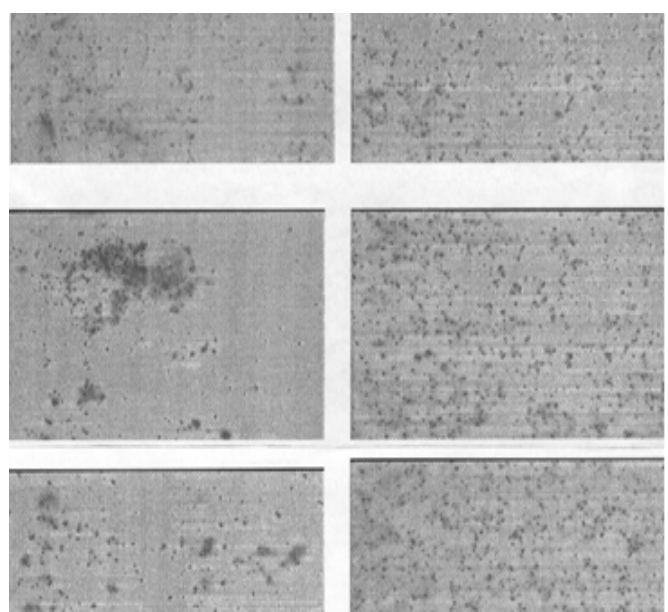

Figure 4. Results of the microscopic analysis of mixing a) without vibration; b) with vibration 


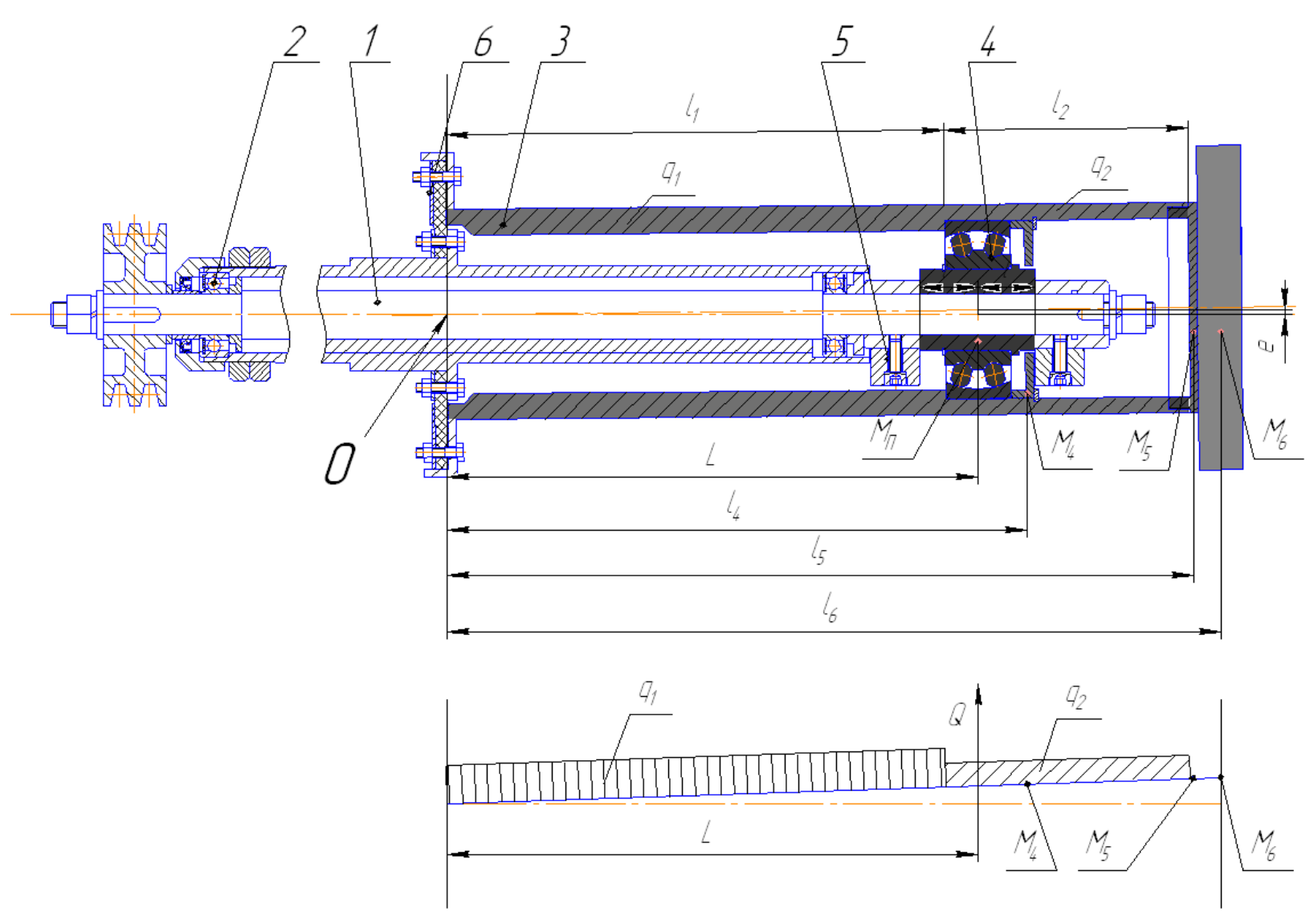

Figure 5. Calculation model

In accordance with the calculation procedure described in detail in (Kuzmichev, 2013; Kuzmichev, 2014; Kuzmichev, Verstov, 2017), the resultant of centrifugal forces $Q$ and its application point (distance $L$ ) are determined taking into account the following equations:

$Q=Q_{1}+Q_{2}+Q_{4}+Q_{5}+Q_{6}=\omega^{2} \operatorname{tg} \beta\left(\frac{1}{2} q_{1} l_{1}^{2}+\right.$

$\left.+\frac{1}{2} q_{2}\left[\left(l_{1}+l_{2}\right)^{2}-l_{1}^{2}\right]+M_{4} l_{4}+M_{5} l_{5}+M_{6} l_{6}\right)$

$L=\frac{Q_{1} l_{1}+Q_{2} l_{2}+Q_{4} l_{4}+Q_{5} l_{5}+Q_{6} l_{6}}{Q}=$

$\frac{\omega^{2} \operatorname{g} \beta\left(\frac{1}{3} q_{1} l_{1}^{3}+\frac{1}{3} q_{2}\left[\left(l_{1}+l_{2}\right)^{3}-l_{1}^{3}\right]+M_{4} l_{4}^{2}+M_{5} l_{5}^{2}+M_{6} l_{6}^{2}\right)}{Q}$

Dynamic balancing is carried out in accordance with the calculation model presented in Figure 6.

In Figure 6, $R, P$ are centrifugal forces resulting from oscillations of the rod bearing assembly and rotation of counterbalances.

The rod bearing assembly is designed and its mass $m_{\text {bearing }}$ and center-of-gravity position are determined. The vibration exciter construction is made with one rod bear- ing center-of-gravity of which is determined at the point of application of the resultant of centrifugal forces.

The mass of the bearing assembly includes the bearing, eccentric part of the bushing and cover. The centrifugal force from the mass of the rod bearing assembly is determined according to the following equation:

$$
R=m_{\text {bearing }} \cdot e \cdot \omega^{2}
$$

The balancing condition is as follows:

$P=1 / 2(Q+R)$

Let us consider calculation of a console plane-parallel four-point vibration activator presented in Figure 7 and installed in a vibration mixer (B type). It consists of carrying drive shaft 1 , main bearings 2 , body 3 , rod bearings 4 installed on the eccentric bushings with mechanically set eccentricity e, counterbalances 5 , oil pump 6, coupling 7 and radiator 8 .

Upon rotation of the carrying drive shaft, the vibration activator body executes circular oscillations with constant amplitude (eccentricity $e$ ).

Calculation of the centrifugal force and its application point is made as follows: 


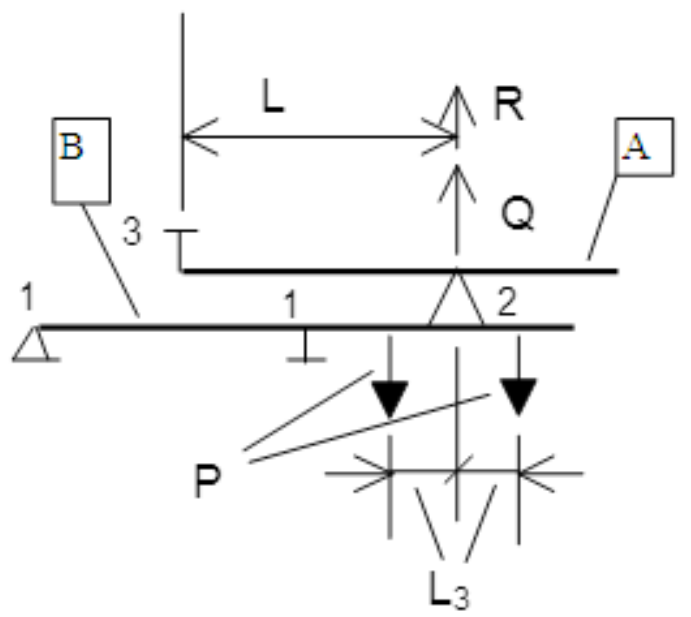

Figure 6. Calculation model

- unbalanced mass $m$ of the vibration activator and its center-of-gravity position - distance $L$ from the body end face - are determined by the known methods using KOMPAS 3D and other programs;

- the centrifugal force resultant is calculated according to the following equation: $Q=m e \omega^{2}$, where $e$ is the value of crank eccentricity (oscillation amplitude); $\omega$ is the angular velocity of rotation of the drive crank shaft of the vibration activator;
- reactive forces $R_{1}$ and $R_{2}$ in the rod bearings are determined by means of statics equations;

- centrifugal forces from masses of the rod bearing assemblies including the bearing itself and eccentric bushing are determined.

Dynamic balancing is carried out in accordance with the calculation model presented in Figure 8.

Balancing condition:

$$
\begin{array}{lc}
P_{1}=1 / 2\left(R_{1}-R_{3}\right), R_{1}>R_{3} & \text { symmetric arrangement of } \\
P_{2}=1 / 2\left(R_{2}+R_{4}\right) & \text { counterbalances }
\end{array}
$$

A geometric shape of counterbalances is chosen according to the recommendations proposed in (Kuzmichev, Verstov, 2017).

As an example, results of measurements of the vibration level on the vibration mixer body (A type) are presented in Table 2. These results reflect the dynamic balancing quality. The measurements were taken using the following measuring equipment: vibration meter of 00032 type, No. 4106, Germany.

Sensors were installed in two diametrically opposite areas on the vibration mixer cover where the drive was placed. The measurements were taken in two modes: experiment № 1 - without any mix in the mixer; experiment № 2 - during mixing.

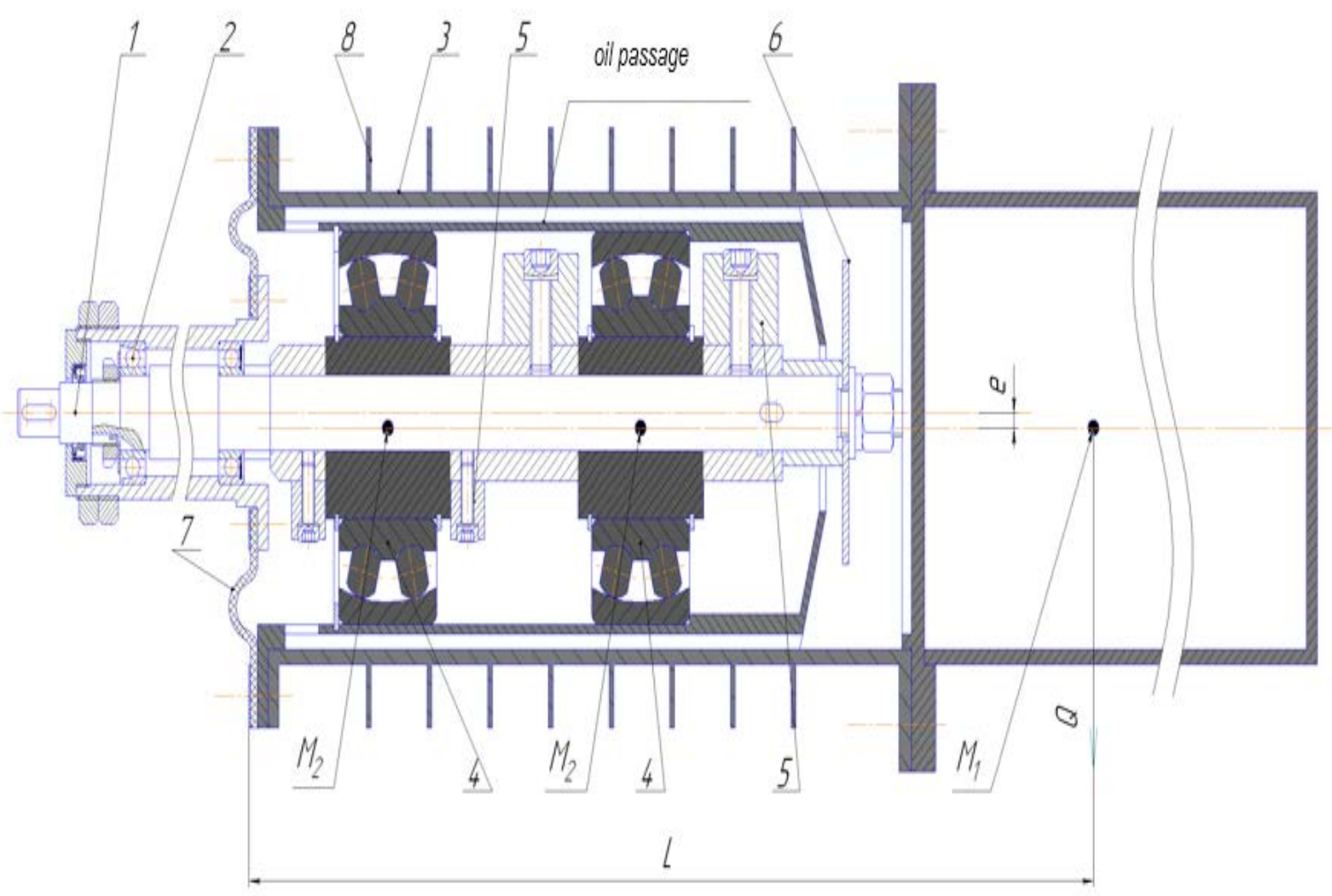

Figure 7. Console plane-parallel four-point vibration activator 
Table 2.

\begin{tabular}{|c|c|c|c|c|c|c|c|}
\hline \multirow[t]{2}{*}{ Experiment № } & \multirow[t]{2}{*}{$\begin{array}{c}\text { Acceleration } \\
\text { of vibration } \\
\text { exciter } \\
\text { oscillations } \\
\mathrm{V}, \mathrm{m} / \mathrm{s}^{2}\end{array}$} & $\begin{array}{c}\text { № of sensor } \\
\text { placement } \\
\text { position }\end{array}$ & $\begin{array}{c}\text { Acceleration } \\
\text { along } \mathrm{X} \\
\mathrm{m} / \mathrm{s}^{2}\end{array}$ & $\begin{array}{c}\text { Acceleration } \\
\text { along } \mathrm{Y}, \\
\mathrm{m} / \mathrm{s}^{2}\end{array}$ & $\begin{array}{c}\text { Acceleration } \\
\text { along } \mathrm{Z}, \\
\mathrm{m} / \mathrm{s}^{2}\end{array}$ & $\begin{array}{c}\text { Root-mean- } \\
\text { square } \\
\text { value, } \mathrm{m} / \mathrm{s}^{2} \\
U=\sqrt{x^{2}+y^{2}+z^{2}}\end{array}$ & $\frac{V}{U}$ \\
\hline & & \multicolumn{3}{|c|}{ measured } & & & \\
\hline 1. & 185 & $\begin{array}{l}\text { № } 1 \\
\text { № } 2\end{array}$ & $\begin{array}{l}2.6 \\
2.5\end{array}$ & $\begin{array}{l}2.8 \\
2.7\end{array}$ & $\begin{array}{l}2.7 \\
3.0\end{array}$ & $\begin{array}{l}4.6 \\
4.7\end{array}$ & $\begin{array}{l}40 \\
39\end{array}$ \\
\hline 2. & 185 & $\begin{array}{l}\text { № } 1 \\
\text { № } 2\end{array}$ & $\begin{array}{l}3.1 \\
3.2\end{array}$ & $\begin{array}{l}2.9 \\
2.8\end{array}$ & $\begin{array}{l}2.7 \\
2.9\end{array}$ & $\begin{array}{l}5.0 \\
5.2\end{array}$ & $\begin{array}{l}37 \\
36\end{array}$ \\
\hline
\end{tabular}

The analysis of the measurement results shows that application of balanced eccentric vibration activators ensures reduction of vibration affecting the environment (drive, frame, etc.) by $\approx 35$ times. The measured peak values of acceleration amount to $\approx 5 \mathrm{~m} / \mathrm{s}^{2}$, corresponding to standard values for processing equipment as per GOST 22061-76.
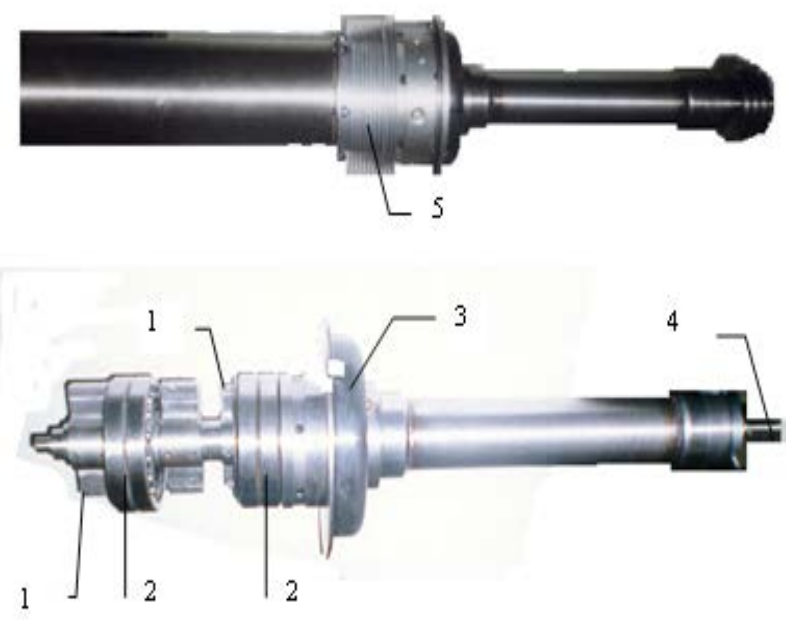

Figure 8. Vibration activator construction: 1 - counterweights, 2 - rod bearing, 3 - clutch, 4 - shaft, 5 - radiator

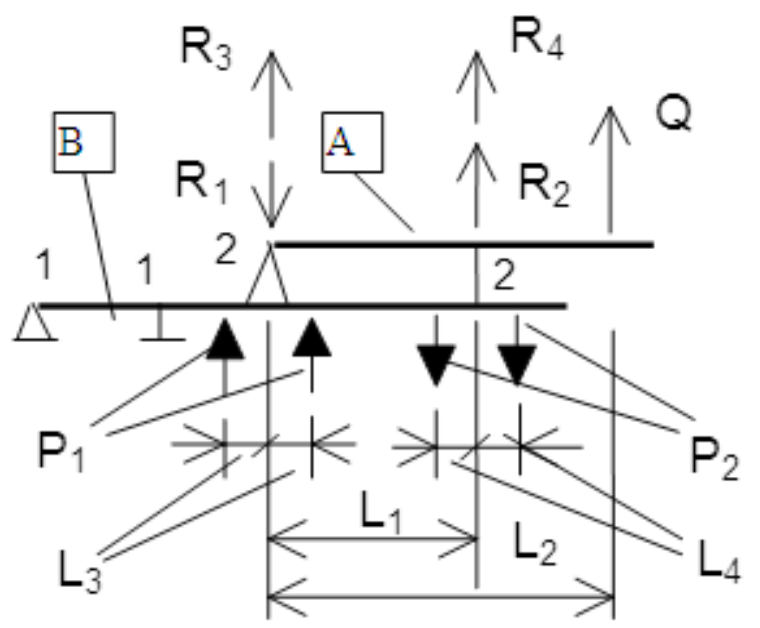

Figure 9. Calculation model

\section{Conclusion}

The presented materials confirm legitimacy of the balancing technique for vibration activators which is presented in detail in (Kuzmichev, 2014), and expediency of their application in mixing equipment for production of construction mixes.

It should be noted that numerous researches in the field of intensification of technological processes with vibration application, conducted by Russian researchers, have shown that the main principles of physical and chemical mechanics of disperse systems can also be successfully used in mixing. Control over structural and rheological properties of mixes at the stage of mixing, in particular, destruction of the structure of mixed materials and, therefore, viscosity reduction, allows increasing uniformity of mixed materials, production quality, affecting molding processes, etc.

It is expedient to use vessel vibration mixers for mixing of highly-concentrated disperse systems, e.g. fillers, dry mixes, powders, paints, etc. 


\section{Architecture and Engineering Volume 2 Issue 2}

\section{References}

Bauman, V.A., Bykhovsky, I.I. (1977). Vibratcionnye mashiny i protcessy $v$ stroitelstve [Vibration machines and processes in construction]. Moscow: Vysshaya Shkola, p.256. (in Russian)

Blekhman, I.I. (1994). Vibratcionnaia mekhanika [Vibration mechanics]. Moscow: Fizmatlit, p.400. (in Russian)

Bosch, H.R.B., Hamersma, H.A., Els, P.S. (2016). Parameterisation, validation and implementation of an all-terrain SUV FTire tyre model. Journal of Terramechanics, 67, pp. 11-23. DOI: 10.1016/j.jterra.2016.06.001

Chelomey, V.N. (1981). Vibratsiya $v$ tekhnike. Spravochnik $v 6$ tomakh [Machinery vibrations. Reference book in 6 volumes]. Moscow: Mashinostroenie Publishing House, vol.6, p.509. (in Russian)

Efremov, I.M., Lobanov, D.V. (2008). Novye rotornye smesiteli s razlichnymi sistemami vibrovozbuzhdeniya [New rotary mixing devices with various systems of vibration activation]. Stroitel'nye i dorozhnye mashiny [Construction and road machinery], 9, pp. 7-9. (in Russian)

Efremov, I.M., Lobanov, D.V. (2009). Vibrobetonosmesiteli: put' dlinoy v 70 let [Vibration concrete finishers: 70 years old experience]. Stroitel'nye i dorozhnye mashiny [Construction and road machinery], 10, pp. 15-19. (in Russian)

Kuzmichev, V.A. (2013). Osnovy proektirovaniya vibromikserov [Basics of designing of vibration mixers]. LAP LAMBERT AcademicPublishing, p.136. (in Russian)

Kuzmichev, V. A. (2014). Osnovy proektirovaniia vibratcionnogo oborudovaniia [Fundamentals of vibration equipment design]. Saint Petersburg: Lan, p.208. (in Russian)

Kuzmichev, V., Verstov, V. (2017). Vibration activators in the construction production technology. Architecture and Engineering, 2(1), pp. 24-32. DOI: 10.23968/2500-0055-2017-2-1-41-50

Verstov, V.V., Tishkin, D.D., Romanovsky, V.N. (2013). Sovershenstvovanie tekhnologii bespodkladochnogo montazha promyshlennogo oborudovaniia [Improvement of the technology of installation of industrial equipment without backing plates]. Installation and special works in construction, 7, pp. 27-31. (in Russian)

Zhang, K.S., Zhu, M., Tang, W.Y., Ou, W.H., Jiang, X.Q. (2016). Algorithm for reconstructing vibrational relaxation times in excitable gases by two-frequency acoustic measurements. Acta Physica Sinica, 65 (13): 134302. DOI: 10.7498/aps.65.134302 